\title{
Spine deformities in patients with Ehlers-Danlos syndrome, type IV - late results of surgical treatment
}

\author{
Barbara Jasiewicz , Tomasz Potaczek, Maciej Tesiorowski, Krzysztof Lokas
}

\begin{abstract}
Background: Spinal deformities in Ehlers-Danlos syndrome are usually progressive and may require operative treatment. There is limited number of studies describing late results of surgery in this disease.

Methods: This is a retrospective study of the records of 11 patients with Ehlers-Danlos syndrome type IV, treated surgically between 1990 and 2007. All patients underwent surgical treatment for spinal deformity. Duration of operation, type of instrumentation, intraoperative blood loss, complications and number of additional surgeries were noted. Radiographic measurement was performed on standing AP and lateral radiographs acquired before surgery, just after and at final follow up.

Results: The mean follow up period was $5.5 \pm 2.9$ years (range 1-10 years). The mean preoperative thoracic and lumbar curve were $109.5 \pm 19.9^{\circ}$ (range $83^{\circ}-142^{\circ}$ ) and $75.6 \pm 26.7^{\circ}$ (range $40^{\circ}-108^{\circ}$ ) respectively. Posterior spine fusion alone was performed on 6 patients and combined anterior and posterior fusion (one- or two stage) on 5 cases. Posterior segmental spinal instrumentation was applied with use of hooks, screws and wires. The mean postoperative thoracic and lumbar curve improved to $79.3 \pm 16.1^{\circ}$ (range $56^{\circ}-105^{\circ}$ ) and $58.5 \pm 27.7^{\circ}$ (range $10^{\circ}$ $95^{\circ}$ ) respectively, with a slight loss of correction during follow up. The average thoracic and lumbar correction was $26.4 \pm 14.9 \%$ (range $5.3-50.4 \%$ ) and $26.3 \pm 21.2 \%$ (range $7.9-75 \%$ ). Postoperatively, the mean kyphosis was $79.5 \pm$ $40.3^{\circ}$ (range $21^{\circ}-170^{\circ}$ ), and lordosis was $50.8 \pm 18.6^{\circ}$ (range $20^{\circ}-79^{\circ}$ ). Hyperkyphosis increased during follow up while lordosis remained stable. Mean Th12-L2 angle was $-3.5 \pm 9.9^{\circ}$ (range $-19^{\circ}-15^{\circ}$ ) postoperatively and did not change significantly during follow up.
\end{abstract}

Conclusions: Huge spinal deformities in patients with Ehlers-Danlos syndrome require complex and extensive surgery. There is a big risk of sagittal imbalance in this group.

\section{Background}

Ehlers-Danlos syndrome is a group of different inherited diseases caused by various defects of collagen metabolism [1]. It is characterized by joint hypermobility and joint laxity. From the description of the first patient by van Meckeren in 1682, it had to pass over 200 years until Ehlers and Danlos published their works and disease called from their names was identified. Current classification consists of 6 types with different genetic abnormalities and various clinical manifestations [2]. Kyphoscoliotic type (type IV) with the deficiency of lysyl

\footnotetext{
*Correspondence: basiajasiewicz@op.pl

Jagiellonian University, College of Medicine, Department of Orthopaedics and Rehabilitation, 34-500 Zakopane, Balzera Street 15, Poland
}

hydroxylase, a collagen modifying enzyme, is of the most interest to orthopedists. Patients suffer from generalized joint laxity, muscle hypotonia at birth, progressive scoliosis and fragility of sclera with risk of ocular globe rupture. Spinal deformity, which typically involves both thoracic and lumbar spine, occurs as scoliosis or kyphoscoliosis and is visible just after birth [3]. Curve progression is rapid and operative treatment is often indicated, however, surgery is not such a simple procedure as in idiopathic scoliosis $[4,5]$.

Surgery is much more difficult due to stiff deformity and is connected with significant risk of serious complications $[5,6]$. That is why individual approach to the treatment of these patients may be advisable. However, there are limited number of studies describing late 
results of operative treatment in patients with Ehlers Danlos syndrome.

The objective of this study was retrospective analysis of spinal deformities in patients with Ehlers Danlos syndrome. In addition we evaluated late results of operative treatment.

\section{Methods}

This is a retrospective study of the records of patients with Ehlers Danlos syndrome type IV, treated surgically between 1990 and 2007. Material consists of 11 patients: 5 females and 6 males. The mean age at the onset of deformity was $1.6 \pm 0.9$ years (range $1-2.5$ years).

All patients had plano-valgus feet, treated operatively in 2 cases. Pectus excavatum was observed in 6 cases, pectus carinatum - in 1 case. Two patients underwent surgical correction of chest deformity. Scoliosis was present in all cases, in all but two it was kyphoscoliosis. Lenke classification was used to categorize the curve types, so type 1 was present in 7 cases, type 3 - in 3 cases and type 5 - in 1 case.

All patients underwent surgical treatment for spinal deformity.

We reviewed preoperative, intraoperative and postoperative records of all patients and noted duration of operation, type of instrumentation, intraoperative blood loss, complications and number of additional surgeries.

Radiographic measurement was performed on standing AP and lateral radiographs acquired before surgery, just after and at final follow up. Preoperative coronal curve flexibility was assessed with use of elongation radiographs. We analyzed: structural curve magnitude according to Cobb, apical vertebral translation (AVT), distance between Th1 and central sacral line (Th1-CSL), trunk shift, thoracic kyphosis and lumbar lordosis, and Th12-L2 angle.

Due to a small number of patients only basic statistical analysis was performed, data are presented as proportions (\%) or as mean with standard deviations and range.

\section{Results}

All patients underwent last clinical and radiographic examination after puberty. The mean follow up period was $5.5 \pm 2.9$ years (range $1-10$ years) and mean age at latest examination was $19.3 \pm 3.9$ years (range 14.2-24.8 years).

\section{Before spine fusion}

The mean age at the first radiogram (available for authors) was $7 \pm 5$ years (range $2-15$ years). The mean Cobb angle of the thoracic curve was $76.3 \pm 37.5^{\circ}$ (range $11^{\circ}-142^{\circ}$ ) and mean angle of the lumbar curve was $60.9 \pm 24,2^{\circ}\left(\right.$ range $\left.38^{\circ}-108^{\circ}\right)$. All patients underwent various non-effective conservative treatment: different exercises and braces (outside our hospital). Spine correction without fusion according to Moe was applied in 5 cases. These patients underwent 3-6 operations with additional distraction before the main surgery.

\section{Pre-operative data}

The mean age at the time of spine fusion was $13.8 \pm 3$ years (range $7-18$ years).

The mean preoperative thoracic and lumbar curve were $109.5 \pm 19.9^{\circ}\left(\right.$ range $\left.83^{\circ}-142^{\circ}\right)$ and $75.6 \pm 26.7^{\circ}$ (range $40^{\circ}-108^{\circ}$ ) respectively. Preoperative flexibility of scoliosis curve was smaller in thoracic than in lumbar region and equaled $22.0 \pm 11.6 \%$ (range $2.5-42.3 \%$ ) and $27.2 \pm 5.2 \%$ (range $18-32 \%$ ) respectively. The mean apical vertebral rotation was $76.8 \pm 34.2 \mathrm{~mm}$ (range 18 $140 \mathrm{~mm}$ ) in thoracic spine, and $25.5 \pm 15.4 \mathrm{~mm}$ (range $0-43 \mathrm{~mm}$ ) in lumbar spine.

The mean absolute value of the distance Th1-CSL was $15 \pm 12.4 \mathrm{~mm}$ (range $0-37$ ). The mean preoperative trunk shift was $17.0 \pm 19.0 \mathrm{~mm}$ (range $-20-45 \mathrm{~mm}$ ). Preoperative thoracic kyphosis and lumbar lordosis were $89.1 \pm 31.2^{\circ}\left(\right.$ range $\left.32^{\circ}-150^{\circ}\right)$ and $55.9 \pm 17.3^{\circ}\left(20^{\circ}-\right.$ $\left.78^{\circ}\right)$ respectively. The value of the Th12-L2 angle varied significantly, with mean preoperative angle $2.6 \pm 23.2^{\circ}$ (range $-36^{\circ}-40^{\circ}$ ).

\section{Spine fusion}

We performed posterior spine fusion alone on 6 patients and combined anterior and posterior fusion (one- or two stage) on 5 cases. Additionally, at the same time thoracoplasty was carried out to improve rib hump in 2 cases. Posterior segmental spinal instrumentation was applied in all cases, with use of hooks, pedicular screws, sublaminar or translaminar wires - depending on technical possibilities and when patients were operated on. The mean operation time was $4.2 \pm 2.6$ hours (range 2.5 - 6 hours). Number of fused vertebra was $11.4 \pm 2.6$ (range 6 - 14) on average. The mean blood loss was 818 $\pm 520 \mathrm{ml}$ (range $200-1800 \mathrm{ml}$ ). There were no intraoperative complications.

During the follow up 4 patients underwent reoperations due to increasing imbalance, instrumentation failure - primary causes were pseudoarthroses in the fused area. Costoplasty improving trunk shape was performed in 2 patients during the follow up.

\section{Post-operative data}

The mean postoperative thoracic and lumbar curve improved to $79.3 \pm 16.1^{\circ}$ (range $56^{\circ}-105^{\circ}$ ) and $58.5 \pm$ $27.7^{\circ}$ (range $10^{\circ}-95^{\circ}$ ) respectively. The average thoracic and lumbar correction percentage was $26.4 \pm 14.9 \%$ (range $5.3-50.4 \%$ ) and $26.3 \pm 21.2 \%$ (range $7.9-75 \%$ ) 
Table 1 Coronal balance data before and after treatment

\begin{tabular}{|c|c|c|c|}
\hline & Before surgery & After surgery & After follow up \\
\hline Thoracic AVT & $\begin{array}{l}76.8 \pm 32.5 \mathrm{~mm} \\
\text { (range } 18-140 \mathrm{~mm} \text { ) }\end{array}$ & $\begin{array}{l}62.5 \pm 29.3 \mathrm{~mm} \\
\text { (range 21-120 mm) }\end{array}$ & $\begin{array}{l}59.4 \pm 17.2 \mathrm{~mm} \\
\text { (range } 35-82 \mathrm{~mm} \text { ) }\end{array}$ \\
\hline Lumbar AVT & $\begin{array}{l}25.5 \pm 15.4 \mathrm{~mm} \\
\text { (range } 0-43 \mathrm{~mm} \text { ) }\end{array}$ & $\begin{array}{l}30.4 \pm 18.7 \mathrm{~mm} \\
\text { (range } 3-63 \mathrm{~mm} \text { ) }\end{array}$ & $\begin{array}{l}33.9 \pm 21.7 \mathrm{~mm} \\
\text { (range } 0-64 \mathrm{~mm} \text { ) }\end{array}$ \\
\hline Absolute Th1-CSL value & $\begin{array}{l}15 \pm 13.1 \mathrm{~mm} \\
\text { (range } 0-37 \mathrm{~mm} \text { ) }\end{array}$ & $\begin{array}{l}32 \pm 18.4 \mathrm{~mm} \\
\text { (range } 5-60 \mathrm{~mm} \text { ) }\end{array}$ & $\begin{array}{l}27 \pm 21.8 \mathrm{~mm} \\
\text { (range } 3-60 \mathrm{~mm} \text { ) }\end{array}$ \\
\hline Trunk shift & $\begin{array}{l}17.0 \pm 20.5 \mathrm{~mm} \\
\text { (range }-20-45 \mathrm{~mm} \text { ) }\end{array}$ & $\begin{array}{l}8.8 \pm 18.3 \mathrm{~mm} \\
(\text { range }-20-30 \mathrm{~mm})\end{array}$ & $\begin{array}{l}19.3 \pm 15.2 \mathrm{~mm} \\
\text { (range } 0-45 \mathrm{~mm} \text { ) }\end{array}$ \\
\hline
\end{tabular}

$\mathrm{AVT}=$ apical vertebral rotation

respectively. There was slight loss of correction during the follow up period, and finally mean thoracic and lumbar curve was $85.2 \pm 12.6^{\circ}$ (range $65^{\circ}-100^{\circ}$ ) and $60.8 \pm 23.7^{\circ}$ (range $15^{\circ}-88^{\circ}$ ) at last examination. Final correction equaled $20.1 \pm 16.6 \%$ (range $0-50.4 \%$ ) and $22.2 \pm 25.6 \%$ (range $-15.8-62.5 \%$ ) respectively. Other coronal plane results are presented in Table 1(Table 1). After surgery, the mean kyphosis was $79.5 \pm 40.3^{\circ}$ (range $21^{\circ}-170^{\circ}$ ), and lordosis was $50.8 \pm 18.6^{\circ}$ (range $\left.20^{\circ}-79^{\circ}\right)$. Thoraco-lumbar junction was slightly lordotic or plane, and mean Th12-L2 angle was $-3.5 \pm 9.9^{\circ}$ (range $\left.-19^{\circ}-15^{\circ}\right)$. Hyperkyphosis increased during the follow up and at last examination mean kyphosis was $94.5 \pm 43.6^{\circ}$ (range $18^{\circ}-180^{\circ}$ ) (additional file 1 ). Lordosis remained stable during the follow up and was $50.2 \pm$ $28.2^{\circ}$ (range $12^{\circ}-90^{\circ}$ ) on average. The mean Th12-L2 angle did not change significantly during the follow up and at last examination it was $-3.1 \pm 22.2^{\circ}$ (range $-40^{\circ}$ $40^{\circ}$ ) (Figure 1).

\section{Discussion}

Etiopathogenesis of collagen defects in Ehlers Danlos syndrome has been already described quite well. One of the most striking symptoms of the disease is kyphoscoliosis, seen in type IV of syndrome. In our

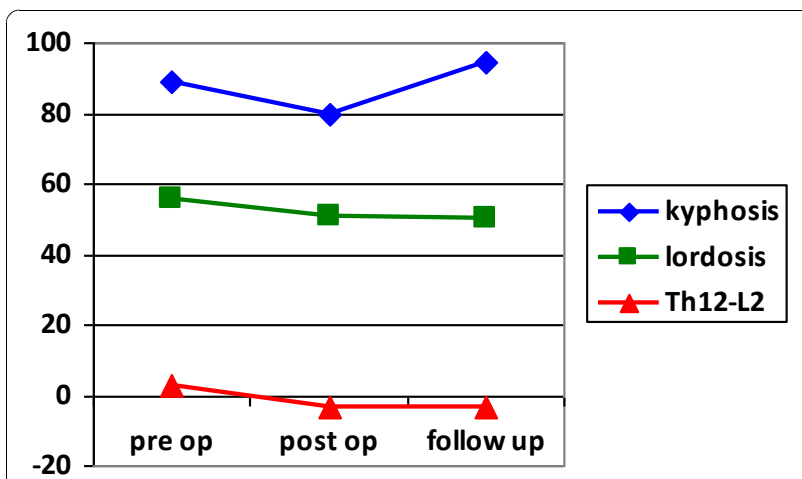

Figure 1 The results of sagittal parameters: kyphosis, lordosis and Th12-L2 angle. patients the onset of spine deformity was assessed below $4^{\text {th }}$ year of life, similarly to patients of McMaster [4]. This deformity is caused by muscle hypotonia and loose ligaments and it can increase to a huge degree. To our knowledge conservative treatment is ineffective. Operative treatment of kyphoscoliosis in Ehlers Danlos syndrome is difficult, and described by other authors "satisfying result" meant certain correction with deformity stabilization, without perfect restoration of sagittal contour $[4,7]$. Main preoperative curve exceeded $80^{\circ}$ in all our patients. Thus, curves were severe with additional disturbances of sagittal contour (Figure 2, 3, $4,5)$. Achieved correction of scoliotic deformity was not big, only just above $26 \%$, comparable to spinal elasticity. Bigger correction was reported by McMaster and Yang, but their patients had minor degree of deformity $[4,8]$. Also brilliant correction was described by Russian authors on 8 patients, but detailed information about this patients' group was not available for us [9]. Blood loss did not exceed $2000 \mathrm{ml}$ in our group and no vascular complications were observed - neither avulsion of segmental arteries via anterior approach nor tear of external iliac artery [5-8]. We did not see any temporary or permanent neurological complications. Coronal plane correction remained stable during follow up and the smaller preoperative curve, the bigger percentage of correction was obtained. Sagittal balance remained a challenging problem; starting with first radiograms, the significant tendency for hyperkyphosis was observed. We found that all 5 patients treated primarily with correction without fusion had increasing kyphosis above the upper end of instrumentation. Generally, kyphosis was stiff, with poor correction during spondylodesis. During follow up sagittal profile worsened, although lordosis and Th12-L2 did not changed significantly, we observed increasing hyperkyphosis. Further reoperations were bound with sagittal imbalance. It is worth emphasizing that due to low frequency of Ehlers-Danlos syndrome, this retrospective study covers years between 1990 and 2007, thus possible operative techniques were limited in the beginning and varied during time. 

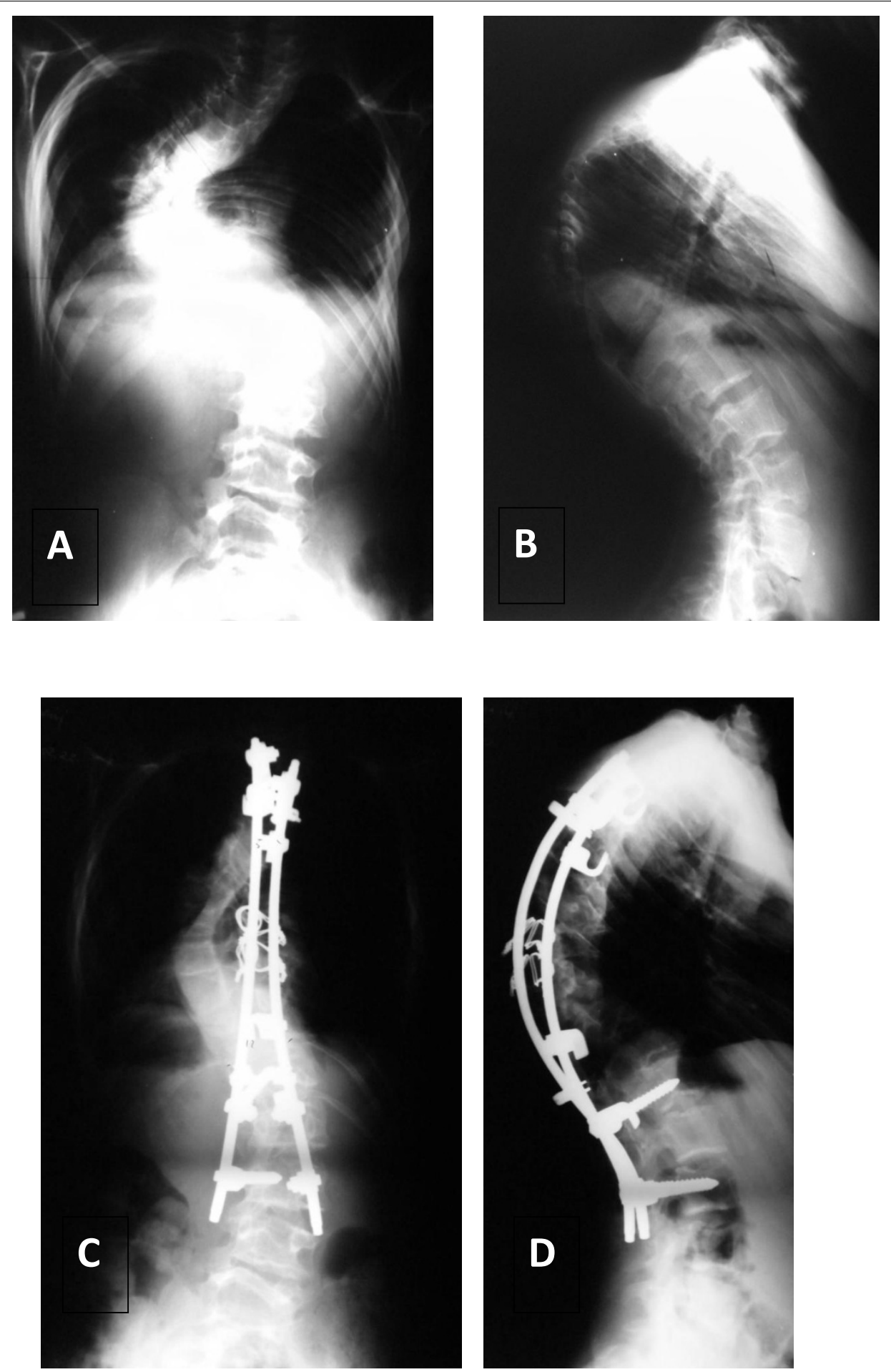

Figure 2 Patient No1, boy, age at surgery: $\mathbf{1 4}$ yrs. Good result after 4 years of follow up. A- AP radiogram before surgery: Cobb angle $105^{\circ}$ B- $L$ radiogram before surgery: kyphosis angle $116^{\circ}, C$ - AP radiogram 4 years after surgery: Cobb angle $60^{\circ}, \mathrm{D}-\mathrm{L}$ radiogram 4 years after surgery: kyphosis $82^{\circ}$. 

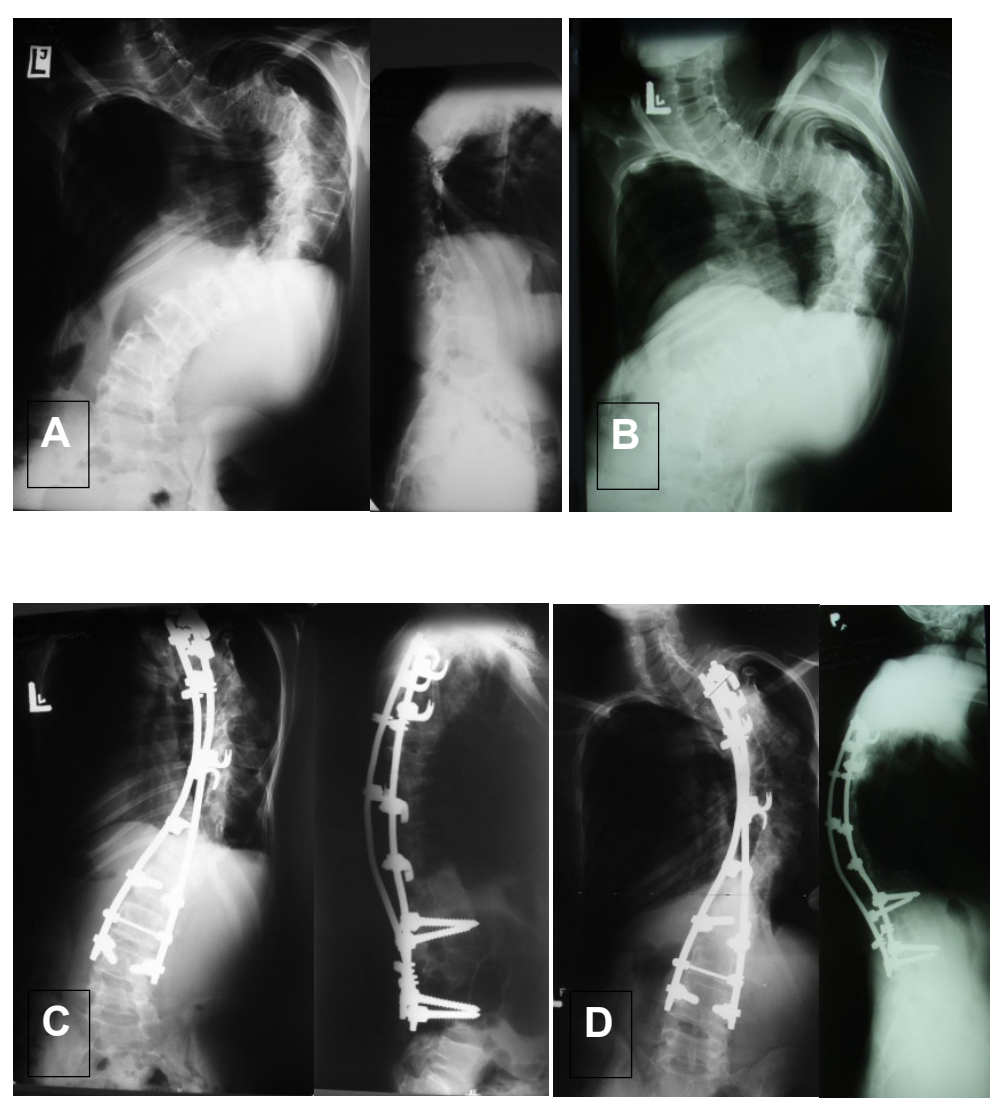

Figure 3 Patient No11, male, age at surgery: 17 yrs. A - AP and L radiograms before surgery, scoliosis angle: $135^{\circ}$, B- radiogram - an oblique view (acc. to Stagnara), C- AP and L radiograms after surgery, D- AP and L radiograms 6 years after surgery. Quite good result, although both coronal and sagittal balance is not ideal.
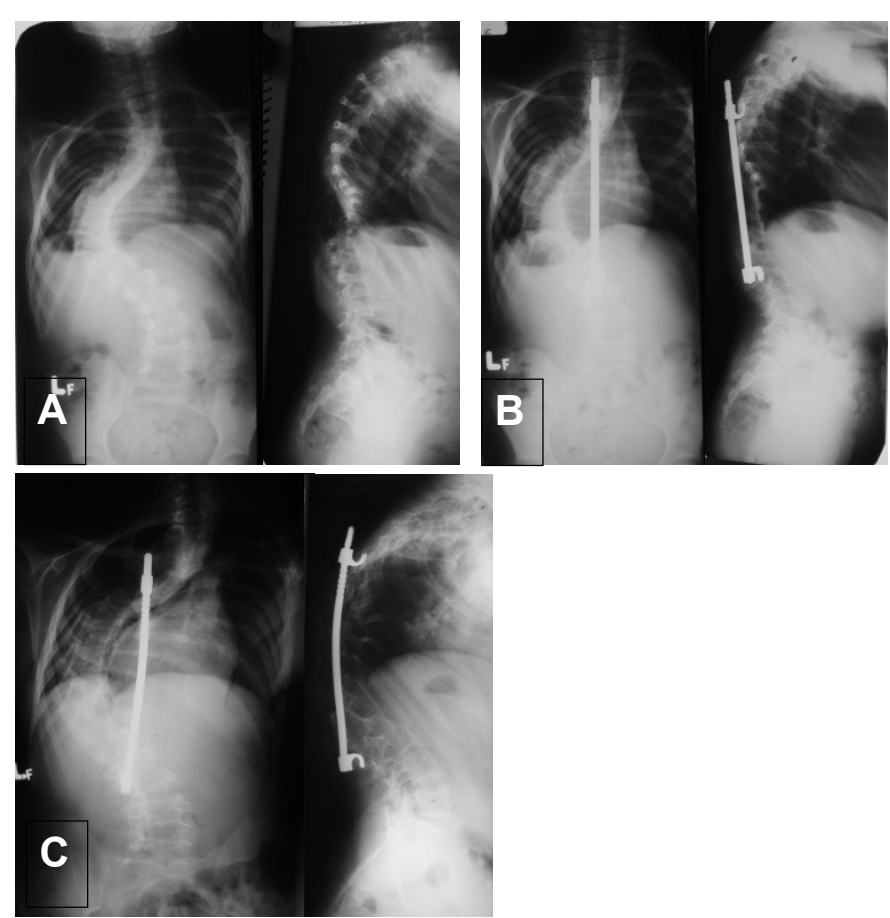

Figure 4 Patient No7, female, age at spinal fusion: 12 yrs. A- first AP and L radiograms at the age of 5; B - correction without fusion (Moe technique); $\mathrm{C}$ - at the age of 12 , just before spinal fusion. Hyperkyphosis above instrumentation. 

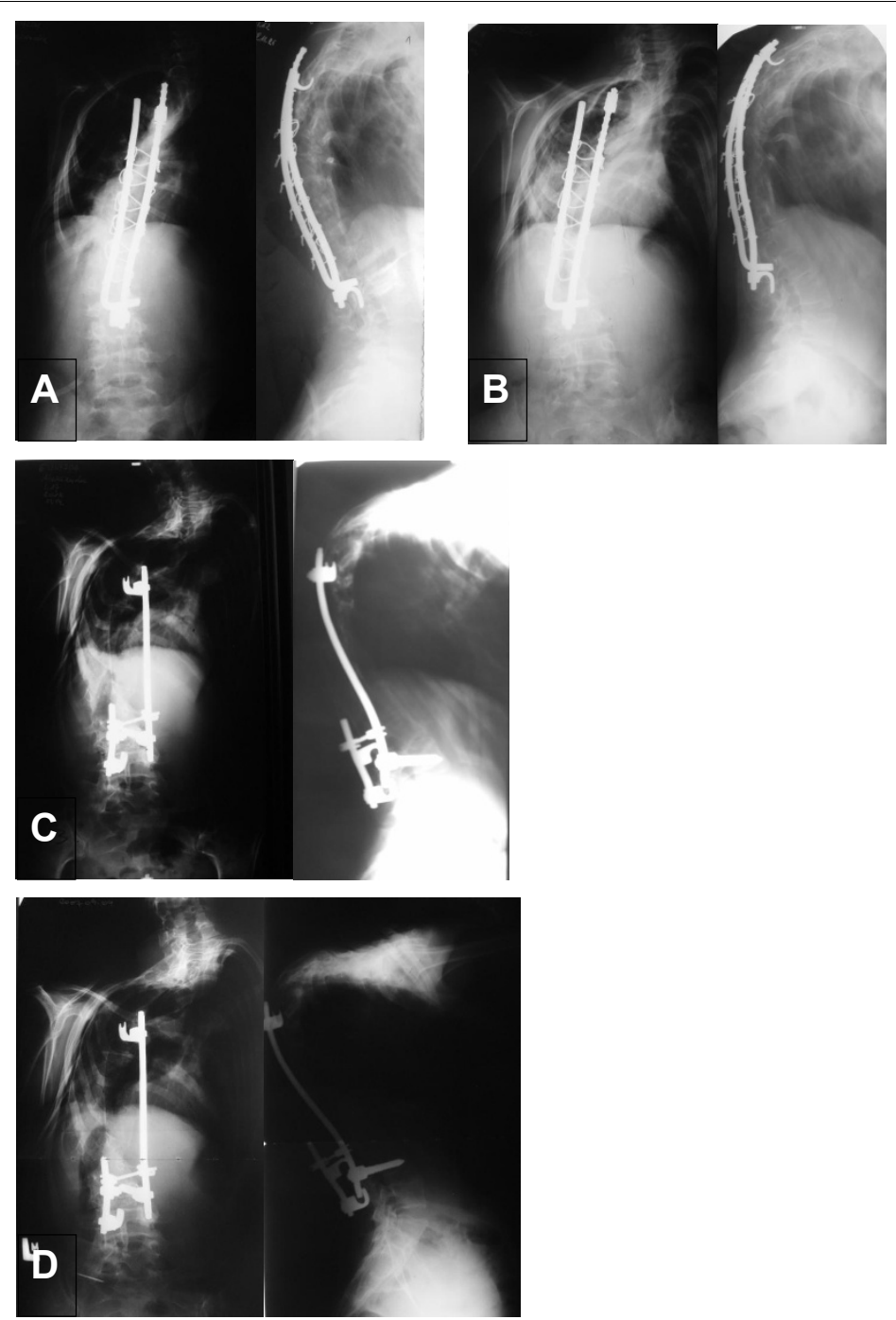

Figure 5 Patient No7, next radiograms:A - after spinal fusion with posterior instrumentation (still kyphosis in upper thoracic region - too short extent of fusion?); B - at the age of 14, spinal decompensation; C- after reoperation: costoplasty, removal of instrumentation, new posterior stabilization at the area of pseudoarthrosis; D- last examination - at the age of 21. Hyperkyphosis, sagittal imbalance.

\section{Conclusions}

Huge spinal deformities in patients with Ehlers-Danlos syndrome require complex and extensive surgery.

There is a big risk of sagittal imbalance in this group.

\section{Additional material}

Additional File 1: Main data of all patients. Microsoft Excel table with data of all patients. the submitted article. All authors give their consent to publish this study and accompanying data.

Study was performed as a part of Research Project No NN 518412936, Polish State Committee for Scientific Research.

\section{Authors' contributions}

BJ conceived of the study, participated in collecting radiologic data and drafted the manuscript

TP participated in the design of the study and performed the statistical analysis in cooperation with $\mathrm{KL}$

MT conceived of the study and participated in its design and coordination $\mathrm{KL}$ participated in collecting radiological data and participated in statistical analysis

All authors read and approved the final manuscript.

\section{Competing interests}

The authors declare that they have no competing interests.

Each author certifies that he has no commercial associations (e.g. consultancies, stock ownership, equity interests, patent/licensing arrangements, etc) that might pose a conflict of interest in connection with
Received: 19 April 2010 Accepted: 25 November 2010 Published: 25 November 2010 


\section{References}

1. Giunta C, Superti-Furga A, Spranger S, Cole WG, Steinmann B: Ehlers-

Danlos syndrome type VIl: clinical features and molecular defects. J Bone Joint Surg Am 1999, 81(2):225-38.

2. Beighton P, De Paepe A, Steinmann B, Tsipouras P, Wenstrup RJ: EhlersDanlos syndromes: revised nosology, Villefranche, 1997. Ehlers-Danlos National Foundation (USA) and Ehlers-Danlos support group (UK). Am J Med Genet 1998, 77(1):31-7.

3. Beighton P, Horan FT: Orthopaedic aspects of the Ehlers-Danlos syndrome. J Bone Joint Surg Br 1969, 51(3):444-53.

4. McMaster MJ: Spinal deformity in Ehlers-Danlos Syndrome. Five patients treated by spinal fusion. J Bone Joint Surg Br 1994, 76(5):773-777.

5. Vogel LC, Lubicky JP: Neurologic and vascular complications of the scoliosis surgery in patients with Ehlers-Danlos syndrome. A case report. Spine 1996, 21(21):2508-2514.

6. Debnath UK, Sharma H, Roberts D, Kumar N, Ahuja S: Coeliac axis thrombosis after surgical correction of spinal deformity in the type VI Ehlers-Danlos syndrome: a case report and review of the literature. Spine 2007, 32(18):E528-31.

7. Akpinar S, Gogus A, Talu U, Hamzaoglu A, Dikici F: Surgical management of the spinal deformity in Ehlers-Danlos syndrome type VI. Eur Spine $J$ 2003, 12(2):135-40

8. Yang JS, Sponseller PD, Muharrem Yazici, Johnston CE: Vascular complications from anterior spine surgery in three patients with EhlersDanlos Syndrome. Spine 2009, 34(4):E153-157.

9. Pozdnikin lul, Ryzhakov luP: [Kypho-scoliotic deformities of the spine in children and adolescents with Ehlers-Danlos syndrome and their treatment]. Ortop Travmatol Protez 1990, , 11: 5-10.

doi:10.1186/1748-7161-5-26

Cite this article as: Jasiewicz et al:: Spine deformities in patients with Ehlers-Danlos syndrome, type IV - late results of surgical treatment. Scoliosis 2010 5:26.

\section{Submit your next manuscript to BioMed Central and take full advantage of:}

- Convenient online submission

- Thorough peer review

- No space constraints or color figure charges

- Immediate publication on acceptance

- Inclusion in PubMed, CAS, Scopus and Google Scholar

- Research which is freely available for redistribution 